EMBRYARIDDLE
Aeronautical University

SCHOLARLY COMMONS

\section{International Journal of Aviation,} Aeronautics, and Aerospace

\title{
To Drive or Fly: Will Driverless Cars Significantly Disrupt Commercial Airline Travel?
}

\author{
Stephen Rice \\ Embry-Riddle Aeronautical University - Daytona Beach, rices15@erau.edu \\ Scott R. Winter \\ Embry-Riddle Aeronautical University - Daytona Beach, scott.winter@mac.com
}

Follow this and additional works at: https://commons.erau.edu/ijaaa

Part of the Other Psychology Commons

\section{Scholarly Commons Citation}

Rice, S., \& Winter, S. R. (2018). To Drive or Fly: Will Driverless Cars Significantly Disrupt Commercial Airline Travel?. International Journal of Aviation, Aeronautics, and Aerospace, 5(1). https://doi.org/10.15394/ ijaaa.2018.1222

This Position Paper is brought to you for free and open access by the Journals at Scholarly Commons. It has been accepted for inclusion in International Journal of Aviation, Aeronautics, and Aerospace by an authorized administrator of Scholarly Commons. For more information, please contact commons@erau.edu. 
Entirely autonomous vehicles are coming. It is no longer debatable if they will come; the question now is when they will be available to consumers. When this happens, the airline industry will be affected. How it is affected is still unknown, but the effects could very well be catastrophic.

We do not claim to be the first people to wonder aloud if the coming driverless vehicle revolution will affect the airline industry (Fairs, 2015; Goldstein, 2017; Radfar, 2017). Nor are we the first to propose that it might crush the airlines by stealing away many of their customers (Javelosa, 2015). However, in the past, most of the opinions relayed about this topic have been just that - opinions. To date, there is very little, if any, real data from consumers indicating how they feel about the future driverless vehicles versus commercial flight battle, nor what their preferences would be in various situations. The purpose of this study is to highlight the issues, present data from a large sample of potential consumers, and to examine what disruptive effects the driverless vehicle revolution will have on the commercial aviation market.

This paper is divided into the following sections. First, we will briefly discuss the current aviation industry, followed by an analysis of current driverless vehicles technology and usage. Then we will highlight several specific scenarios where driverless vehicles will compete with the airline industry once genuinely autonomous cars hit the roads. Next, we will discuss how the disruptive nature of driverless cars will affect the airline industry, and where the most significant changes will be seen. Following this, we will consider how driverless vehicles may affect airports and other supporting industries. Finally, we will offer our closing thoughts on what the consumers have to say, and why they matter the most.

\section{Current Aviation Industry}

The current aviation industry is going through a rather robust economic period. Airlines are profitable as the economy within the United States is growing. Current challenges relate to pilot staffing levels and airport capacity. The market also seems to support legacy airlines such as American, United, Delta, and Alaska; low-cost carriers such as Southwest, JetBlue; and ultra-low-cost carriers such as Spirit, Allegiant, and Frontier. However, this increase in revenue has come at a cost, specifically to the consumer. Passengers are now charged for many of the amenities that were once free such as checking luggage, onboard snacks, selecting seats, and boarding order. Airport security has also been tightened to require most passengers to remove shoes, electronics, and liquids before going through the security process. Often times even a short one-hour flight results in a 5 to 6-hour ordeal between travel time to the airport, arriving with sufficient time before departure, waiting to 
check-in, waiting for security, any flight delays, the actual flight, waiting for luggage on arrival, establishing ground transportation at the destination, and finally traveling to their final location within that city. For trips of less than 6 hours, it may be just as quick to drive than fly. However, driving can be stressful as well, and that results in 6 hours of unproductivity to focus on driving. However, the future implementation of driverless vehicles could result in significant shifts to travel preferences for transportation.

\section{Current Driverless Vehicles Technology and Usage}

There are no current fully autonomous vehicles on the road in the United States. There are vehicles with varying levels of automated functions, but in all cases, a human driver still has access to the controls of the vehicle and often has to take over when the autopilot fails (Bogost, 2016). This applies to cars (Somerville $\&$ Sage, 2016), trucks (Davies, 2017) and other types of vehicles. While some companies such as General Motors (Davies, 2018) have proposed that they will have fully autonomous cars on the road "within a year", we have heard these types of reports before, so it is difficult to tell with certainty if a car with no steering wheel or brakes will actually be sold in the United States anytime soon. Furthermore, there are legal issues to work out before different states will allow this to happen.

What is available currently are cars with varying levels of automated assists. These can include lane-keeping, sense and avoid, automatic braking, blind spot detection, adaptive cruise control, etc. Some of the most advanced autopilot technology is seen in the Tesla vehicles (Bogost, 2016), but this company still requires that the driver be alert and in full supervisory control of the vehicle. Thus, it is unlikely that the current crop of automated vehicles will have much impact on the aviation industry because people recognize that they still must drive the car, and are still subject to the same fatigue and boredom issues that plague long-distance vehicular travel.

When personal vehicles do become fully autonomous, and cars can be ridden in rather than driven, then we expect that this will have a significant fundamental impact on the aviation industry. It is not unreasonable to ask the question: Should I fly or should I ride in my driverless car?

\section{Would I Fly or Ride in a Driverless Vehicle?}

In this section, we focus on specific scenarios where we discuss potential choices between driverless vehicles and commercial flight. We will present five 
scenarios with different flight and drive times and describe the advantages and disadvantages of driverless vehicle travel compared to a commercial airline flight. Also, we present consumer data from over 2,000 survey respondents with an average age of $35.86(S D=11.57$; Range $=18-76)$ indicating what their preference would be in each of the following situations. While it is easy for the authors to have an opinion about these types of choices, we feel that the argument is made more salient with actual data from consumers.

Imagine a scenario where you live in Fairfax, Virginia, which is a suburb of Washington DC. You wish to travel to New York City to see the Empire State Building. You are traveling alone. You plan to arrive there at 3:00 PM the following day. To take this trip via commercial airline, you would need to arrive at a New York airport by 2:00 PM to catch a taxi to get you to the specific location. This means departing from Dulles or Reagan National around 1:00 PM. You need to arrive at the airport 2 hours before your flight, which would be 11:00 AM. You must leave your house 30-60 minutes before that to ensure that you make the flight on time. In summary, your total travel time is from 10:00 AM to 3:00 PM, or 5 hours. Google Maps indicates that you can make the drive in 4 hours 46 minutes in average traffic. In other words, you can choose between two options with almost identical travel times. Which would you prefer?

Some people may prefer to drive, but others may prefer to fly because the drive is stressful, and they don't want to worry about being tired upon arrival. Furthermore, they may not want to park their car in New York City. In our survey, $33.67 \%$ of the total respondents indicated that they would prefer to fly commercial. See Table 1 for a complete data set of all the scenarios.

Now imagine that you have a driverless car that can navigate you to your destination with no input whatsoever from the driver. In fact, you can lie down and sleep or watch a movie while your driverless car transports you to New York City. Now, which choice would you prefer? In our survey, $33.27 \%$ of the total respondents indicated that they would prefer to fly commercial. This is a small drop from the situation where they must manually drive the car. When participants were told that they needed a car during their stay in NYC, and flying commercial would require them to rent a car, the percentage of people who preferred commercial flight dropped to $26.10 \%$ or a $7.57 \%$ drop from the initial condition.

In our second scenario, imagine that you want to travel from Kansas City to Chicago. Again, the total travel time flying commercial will be around 5 hours, depending on where you live in Kansas City and where you plan to go in Chicago. Google Maps indicates that this is a 7-hour drive in normal conditions. Does the 
more extended drive make you more likely to fly commercial? In our survey, $61.95 \%$ of the total respondents indicated that they would prefer to fly commercial if they had to drive manually, while only $45.22 \%$ wanted to fly commercial if they had a driverless car - a $16.73 \%$ drop. When participants were told that they needed a car during their stay in Chicago, and flying commercial would require them to rent a car, the percentage of people who preferred commercial flight dropped even further to $32.67 \%$, or a massive $30 \%$ drop from the current state of travel.

Table 1

Percentage of consumers who would prefer to fly commercial in the various scenarios. The last column indicates the total percentage drop from the current state of travel to a situation where a person has a driverless car and no longer needs to rent a car at the destination.

\begin{tabular}{|c|c|c|c|c|}
\hline & Manual Cars & Driverless Cars & Need a Rental Car & Total Reduction \\
\hline 5-hour Drive & 33.67 & 33.27 & 26.1 & 7.57 \\
\hline 7-hour Drive & 61.95 & 45.22 & 32.67 & 29.28 \\
\hline 11-hour Drive & 84.26 & 67.53 & 56.18 & 28.09 \\
\hline 21-hour Drive & 87.85 & 80.68 & 73.51 & 14.34 \\
\hline 45-hour Drive & 88.65 & 83.86 & 80.28 & 8.37 \\
\hline
\end{tabular}

From Detroit to Atlanta is about 6 hours of total travel time flying commercial, but more than 11 hours when driving. In this scenario, 84.26\% of the total respondents indicated that they would prefer to fly commercial if they had to drive manually, while only $67.53 \%$ wanted to fly commercial if they had a driverless car - a $16.73 \%$ drop. When participants were told that they needed a car during their stay in Atlanta, and flying commercial would require them to rent a car, the percentage of people who preferred commercial flight dropped even further to $56.18 \%$ or a $28.09 \%$ drop from the initial condition; again, a very large drop from the current state of travel.

From Tucson, Arizona to New Orleans is a 21-hour drive, versus about 6.5 hours of total travel time flying commercial. $87.85 \%$ of the total respondents indicated that they would prefer to fly commercial if they had to drive manually, while $80.68 \%$ wanted to fly commercial if they had a driverless car-a $7.17 \%$ drop. When participants were told that they needed a car during their stay in New Orleans, and flying commercial would require them to rent a car, the percentage of people who preferred commercial flight dropped even further to $73.51 \%$ or a $14.34 \%$ drop from the initial condition.

From Seattle, Washington to Orlando, Florida is a 45-hour drive, versus about 7.5 hours of total travel time flying commercial. $88.65 \%$ of the total 
respondents indicated that they would prefer to fly commercial if they had to drive manually, while $83.86 \%$ wanted to fly commercial if they had a driverless car-a $4.78 \%$ drop. When participants were told that they needed a car during their stay in Orlando, and flying commercial would require them to rent a car, the percentage of people who preferred commercial flight dropped even further to $80.28 \%$ or an $8.37 \%$ drop from the initial condition.

\section{How Does This Affect the Airline Industry?}

Driverless cars could impact the airline industry in many ways. First, they could contract the industry. If individuals decide to take personal transportation over the airlines, there will be less demand and paying customers. As one example, the spoke of the hub and spoke model might be reduced. For many airlines, their network structure consists of funneling a number of flights into a hub, shuffling passengers, and then sending aircraft back out to the spokes in the network (Adler, 2005; Adler \& Smilowitz, 2007; Alderighi, Centro, Nijkamp, \& Rietveld, 2007). Instead of completing the hour-long flight from the spoke airport to the hub, passengers may instead just decide to travel directly to the hub. This could be advantageous for some reasons, such as reducing the chance of flight delays, missing a connection at the hub, and reducing the need for a layover. Take for example an international flight departing out of Atlanta. For passengers that live within 4-5 hours of the hub, they may just decide to use a driverless vehicle to travel to the hub instead of purchasing and completing the spoke part of the itinerary. Then they may send that driverless vehicle back home alone, so they do not have to pay the parking fees during an extended trip.

Examples such as these could have a cascading effect. For instance, if fewer individuals complete the spoke flight, less demand may result in fewer flights offered, and this lack of flight options could potentially increase the number of passengers that choose to use a driverless vehicle due to the reduction in flight offerings. If the spokes become reduced, airlines may have to focus on transcontinental and international flights, which due to length or terrain may not be feasible for driverless cars. A reduction in flights could also result in changes to the demand for pilots, flight attendants, and other airline employees.

Manufacturers could feel the impact as well. Airlines may be forced to reduce the fleet size or may modify growth plans if the industry receives a disruption due to driverless vehicles. Fleet distribution may change as well if airlines lessen the focus on regional routes and instead focus on transcontinental and international flights. 
There could be other related factors as well. Passengers are not restricted in their packing of items, such as liquids if traveling in a personal vehicle. There are no security lines, or delays await inbound aircraft or crew changes. Elderly individuals may be more prone to driverless cars as they do not have to travel through the airport, board multiple flights, and handle security concerns. Travelers may also find value in the ability to come and go as they please, something which has become a challenge with airline travel due to most airlines charging rather large change fees for any unplanned itinerary modifications.

\section{Airports and Other Supporting Industries}

A reduction in flights could also have an impact on the area surrounding airports, resulting in disruptions not only to the airlines, but also support industries like hotels (Fairs, 2015). Fewer flights would likely result in few customers staying in hotel rooms. Parking lots could also be affected as parking would shift from being centered around the airport to where ever the destination is for the driverless vehicle. Alternatively, in driverless vehicles, passengers could decide to skip the hotel room and just sleep in the car while the driverless vehicles transport them to their destination.

\section{Closing Statement}

The aviation industry will be affected by the rise of entirely autonomous automobiles. Once people have access to a car that will handle every aspect of driving, and they can watch a movie or even sleep while riding, then the current data suggest that this could have a catastrophic effect on commercial flight. Even if only $10 \%$ of the flying public decides to switch to driverless cars, this will bankrupt many smaller airlines (mainly the short-haul flights) and have a significant adverse impact on the cross-country flights as well. Airlines will have to reduce the number of flights per day, which could create snowball effects of pushing even more passengers to driverless vehicles because their flight choices are not as flexible as they once were. If a much more significant percentage of the flying public moves to driverless vehicles, then the entire industry could see a contraction similar to what happened to the rail system when interstates became ubiquitous. Only the overseas or very long-haul flights would be immune. And even in those cases, passengers may choose to skip the spoke and go straight to the hub for their international flight, reducing the potential airline profit, along with all the supporting industries (e.g., parking, hotels, fuel, etc.).

We close by saying that some may already recognize this problem, but it is not nearly as discussed as it needs to be. Recent conversation at the Transportation 
Research Board meeting in Washington, D.C., led both authors to believe that many of the administrators in the airline industry and the FAA have not given this much consideration. Perhaps it is time to start thinking about it before the hammer hits. 


\section{References}

Adler, N. (2005). Hub-spoke network choice under competition with an application to Western Europe. Transportation Science, 39(1), 58-72.

Adler, N. \& Smilowitz, K. (2007). Hub-and-spoke network alliances and mergers: Price-location competition in the airline industry. Transportation Research Part B, 41, 394-409.

Alderighi, M., Centro, A., Nijkamp, P., \& Rietveld, P. (2007). Assessment of new hub-and-spoke and point-to-point airline network configurations.

Transport Reviews, 27(5), 529-549.

Bogost, I. (2016). When cars fly. The Atlantic. Retrieved from: https://www.theatlantic.com/magazine/archive/2016/05/when-carsfly/476382/

Davies, A. (2017). Self-driving trucks are now delivering. Wired. Retrieved from: https://www.wired.com/story/embark-self-driving-truck-deliveries/

Davies, A. (2018) GM will launch robocars without steering wheels next year. Wired. Retrieved from: https://www.wired.com/story/gm-cruise-selfdriving-car-launch-2019/

Fairs, M. (2015). Driverless cars could spell the end for domestic flights. Dezeen. Retrieved from: https://www.dezeen.com/2015/11/25/self-drivingdriverless-cars-disrupt-airline-hotel-industries-sleeping-interview-audisenior-strategist-sven-schuwirth/

Goldstein, M. (2017). How autonomous cars could disrupt airlines, hotels and rental agencies. Retrieved from:

https://www.forbes.com/sites/michaelgoldstein/2017/07/07/howautonomous-vehicles-will-change-your-travel-experience/\#6033ab307161

Javelosa, J. (2015). Will driverless cars put the hotel and airline industry in danger? Futurism. Retrieved from: https://futurism.com/will-driverlesscars-put-hotel-airline-industry-danger/ 
Radfar, C. (2017). Dear United: Autonomous cars will pull you out of your seat. Crunch Network. Retrieved from:

https://techcrunch.com/2017/07/16/dear-united-autonomous-cars-willpull-you-out-of-your-seat/

Somerville, H. \& Sage, A. (2016). Uber launches self-driving car fleet in San Francisco despite warning from regulator. Reuters. Retrieved from: https://www.reuters.com/article/us-uber-selfdriving/uber-launches-selfdriving-car-fleet-in-san-francisco-despite-warning-from-regulatoridUSKBN143265 